\title{
Em defesa da escola bilíngue para surdos: a história de lutas do movimento surdo brasileiro
}

\section{In defense of the Bilingual School for the deaf: the history of fights of the Brazilian Deaf Movement}

\author{
Ana Regina Campello ${ }^{1}$ \\ Patrícia Luiza Ferreira Rezende ${ }^{2}$
}

\begin{abstract}
RESUMO
Este artigo apresenta a trajetória histórica do Movimento Surdo em defesa das Escolas Bilíngues para Surdos, ao longo dos últimos anos, quando da iminente ameaça de fechamento da escola centenária, o Instituto Nacional de Educação de Surdos, em 2011, provocando uma mobilização sem precedentes para a inclusão das Escolas Bilíngues para Surdos no Plano Nacional de Educação - PNE, hoje sancionado pela Lei 13.005/2014. Lutamos por uma Política Nacional de Educação Bilíngue condizente para a formação da Identidade Linguística da Comunidade Surda, garantida pela Convenção Internacional sobre Direitos das Pessoas com Deficiência, que reconhece a importância da Língua de Sinais e da Cultura Surda para as Pessoas Surdas.

Palavras-chave: Educação Bilíngue; Movimento Surdo; história; Língua de Sinais; Cultura Surda.
\end{abstract}

\begin{abstract}
This article presents the historical path of the Deaf Movement in defense of Bilingual Schools for the Deaf, throughout the past years, brought about by the imminent threat of the closing of the centenary INES (National Institute
\end{abstract}

DOI: $10.1590 / 0104-4060.37229$

1 Universidade Federal do Rio de Janeiro. Rio de Janeiro, Rio de Janeiro, Brasil. Av. Horácio Macedo, 2151, sala D-104, Cidade Universitária. CEP: 21941-917.

2 Instituto Nacional de Educação de Surdos. Rio de Janeiro, Rio de Janeiro, Brasil. Rua das Laranjeiras, 232. CEP: 22240-003. 
of Deaf Education) school in 2011, that led to an unprecedented mobilization towards the inclusion of Bilingual Schools for the Deaf in the PNE (National Plan of Education) - currently sanctioned by the law 13.005/2014. We fight for a bilingual PNE consistent with the Linguistic Identity formation of the DeafCommunity, guaranteed by the UN Convention on the Rights of Persons with Disabilities, which recognizes the importance of Sign Language and Deaf Culture for Deaf People.

Keywords: Bilingual education; Deaf Movement; history; Sign Language; Deaf Culture.

"Nada sobre nós, surdos, sem nós, surdos!"

Esta é a história das lutas em defesa da Escola Bilíngue de Surdos nestes últimos anos, uma história que foi e ainda é uma explosão de mobilizações sem precedentes, em que surdos de praticamente todas as regiões do país foram mobilizados e mobilizadores para defender a qualidade da educação para nossas crianças surdas.

Nós vivenciamos essa história. Primeiramente como surdas, representantes das comunidades surdas brasileiras e, em segundo lugar, como pesquisadoras, com espírito ativista. Não podemos negar a nossa história, intensamente ligada ao diagnóstico do campo de lutas e batalhas. No dizer de Foucault:

O problema político essencial para o intelectual não é criticar os conteúdos ideológicos que estariam ligados à ciência ou fazer com que sua prática científica seja acompanhada por uma ideologia justa; mas saber se é possível constituir uma nova política da verdade. O problema não é mudar a "consciência" das pessoas, ou o que elas têm na cabeça, mas o regime político, econômico, institucional de produção da verdade. (FOUCAULT, 1979, p. 14).

Somos intelectuais em busca de uma produção política legítima para a educação dos surdos, que significa uma política educacional permeada pelas necessidades e anseios dos alunos; uma política que condiz com nossa luta, com nossas experiências de vida, com nossos anseios pelos e ao lado de nossos pares surdos, em busca do direito de as crianças surdas terem, desde a mais tenra idade, a possibilidade de adquirir a Identidade Linguística da Comunidade 
Surda. Arthières (2004) tem razão quando descreve o pensamento de Foucault sobre a posição do intelectual específico, "que não expunha um discurso sobre os acontecimentos, mas atravessava fisicamente cada um deles, e era dessa experiência única que um verdadeiro diagnóstico podia emergir” (p. 37).

Somos autoras com atravessamentos produzidos por uma política pública educacional que não atendeu e não atende às nossas imperativas demandas linguísticas e culturais. Nós diagnosticamos em nosso campo a imperativa necessidade da Educação Bilíngue de Surdos. A partir desse lugar que falamos, contamos a história das lutas do Movimento Surdo Brasileiro em defesa das nossas Escolas Bilíngues.

A história em defesa das nossas escolas específicas vem de tempos longínquos. A língua de sinais e a cultura surda, em sua imensidão, compartilhada entre os pares surdos, travou-se em períodos de proibições do uso da nossa língua, por imposições ouvintistas, sempre entremeadas de muitas lutas pela sobrevivência da nossa língua de sinais e pela qualidade da nossa educação.

A história de lutas aqui tratada teve início no ano de 2010 e foi marcada pela maior mobilização da história de todo Movimento Surdo Brasileiro. O início dessa história deu-se durante a realização da Conferência Nacional da Educação, CONAE 2010, no período de 28 de março a $1^{\circ}$ de abril de 2010. Os resultados dessa Conferência serviram de base para a elaboração do Plano Nacional da Educação - PNE. Este evento marcou um retrocesso na educação de surdos, a partir do momento em que a proposta dos delegados surdos presentes nesta Conferência não foi atendida. A edição 40 da Revista da Feneis, de junho a agosto de 2010, apresentou uma matéria intitulada: "Conferência Nacional de Educação rejeita a proposta que apoia a escola de surdos". Vejamos as cenas desta Conferência relatadas pela Jornalista Regiane Lucas:

Na opinião dos surdos usuários da Língua de Sinais sobre a conferência, a regra da maioria não se mostrou a mais democrática. Das onze propostas defendidas pelos representantes da comunidade surda, apenas três foram aprovadas. [...] Em geral, as propostas defendidas pelos representantes da comunidade surda visavam a manutenção e criação de escolas bilíngues para surdos. Segundo o delegado Neivaldo Zovico, houve um forte lobbie das entidades favoráveis à escola inclusiva, perspectiva também apoiada pelo governo. Ele explica que a conferência foi dividida em seis subtemas e que as propostas sobre os surdos entraram no eixo seis "Justiça social, educação e trabalho: inclusão, diversidade e igualdade". "Durante a fase de discussão interna ao eixo seis fizemos um acordo de que todos votaríamos a favor das propostas apresentadas pelos diferentes grupos - negros, quilombolas, Movimento dos Sem Terra, dentre outros. 
Partimos do princípio de que ninguém conhece melhor a realidade do que aqueles que a vivenciam", relata o delegado, que também é professor. No momento da votação, sete propostas foram totalmente rejeitadas, três aprovadas com $50 \%$ e uma obteve $30 \%$. Neivaldo argumenta que os dirigentes governistas manipularam o grupo. "Nas nossas costas, depois de sairmos da plenária, os participantes do eixo seis foram chamados para uma reunião com representantes do Governo Federal e de ONGs conveniadas ao Ministério da Educação (MEC). Eles os convenceram a votar contra as propostas destacadas pelo grupo de surdos, acusando nossas ideias de segregacionistas. Os únicos movimentos que nos apoiaram até o fim foram a Liga Brasileira de Lésbicas (LBL) e a Educação do Campo", explica Neivaldo (LUCAS, 2010, p. 22-23).

Os delegados surdos no CONAE 2010 entregaram-nos um panfleto feito pela equipe da então Secretaria de Educação Especial - SEESP/MEC, hoje absorvida pelo SECADI/MEC ${ }^{3}$, acusando as escolas de surdos de serem segregadas.

Os delegados surdos pediram a inclusão da seguinte emenda ao documento da CONAE 2010, que seria a base para o Projeto de Lei do PNE: Garantia às famílias e aos surdos do direito de optar pela modalidade de ensino mais adequado para o pleno desenvolvimento linguístico, cognitivo, emocional, psíquico, social e cultural de crianças, jovens e adultos, garantindo o acesso à educação bilíngue - utilizando a Língua Brasileira de Sinais (LIBRAS) e a língua portuguesa.

A equipe da, então, SEESP fez um forte lobby para rejeitar a emenda. Foi distribuído um panfleto entre os delegados no qual rejeitavam a emenda sob a justificativa de que ela "reforça a organização de escolas segregadas com base na diferenciação pela deficiência contrariando a concepção da educação inclusiva" (LUCAS; MADEIRA, 2010, p. 23).

Na matéria da Revista da Feneis (2010b) está o registro de que a Diretora de Políticas Educacionais Especiais do MEC, Martinha Claret, rebateu o delegado surdo Neivaldo Zovico dizendo que não houve acordos e lobbies e ainda acrescentou que:

A conferência é um espaço democrático e o resultado foi fruto do debate. A maioria da plenária reconheceu que há um princípio da educação inclusiva a ser seguido e que votar pela escola de surdos é ir contra esse princípio. Além disso, não há ONG ligada ao ministério. Muitos delegados são

3 Secretaria de Educação Continuada, Alfabetização, Diversidade e Inclusão, do Ministério da Educação. 
ligados a entidades e movimentos, mas todo o contingente fez parte do debate. Ao MEC coube apresentar argumentos em defesa das orientações do governo e das políticas educacionais vigentes (FENEIS, 2010b, p. 23).

Depois disso, a Diretora de Políticas de Educação Especial Martinha Claret, com os pensamentos retrógrados sobre a nossa educação, ainda ousou ir ao Instituto Nacional de Educação de Surdos (INES), em 17 de março de 2011, para comunicar ao seu Conselho Diretor, diante da presença de alunos, professores e pais, que o Colégio de Aplicação do INES seria fechado até o final de 2011 e os alunos surdos seriam remanejados para escolas comuns.

Esse comunicado provocou um mal-estar na comunidade escolar e chegou ao conhecimento do líder surdo Nelson Pimenta, atual professor efetivo do INES, que gravou um vídeo alertando toda a comunidade surda brasileira e mundial sobre a ameaça do fechamento do INES. Abaixo, apresentamos o vídeo postado por Pimenta (Figura 1), em 24 de março de 2011, uma semana após o comunicado oficial da técnica Martinha Claret ao Conselho Diretor do INES, acompanhado de tradução feita por alunos, com orientação dos professores da área de tradução de Letras Libras da UFSC:

A Feneis alertou várias vezes sobre o equívoco da política de educação inclusiva imposta pelo MEC. Essa política provocou fechamento de várias escolas de surdos pelo país. Esses alertas foram registrados pelas seguintes

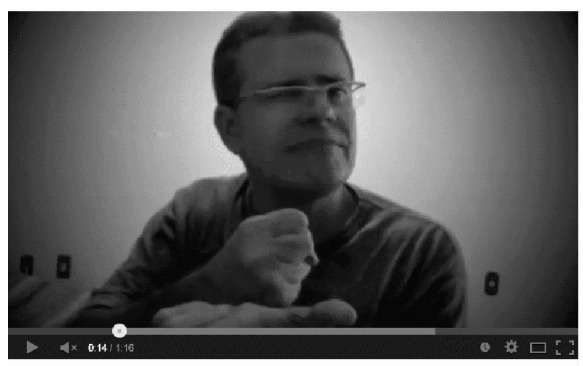

Fechamento do INES. Absurdo!!!!

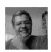

alson Pimenta - 128 videna

$\checkmark$ inscritu

FIGURA 1 - DEPOIMENTO DE NELSON PIMENTA FONTE: http://www.youtube.com/watch? $\mathrm{v}=\mathrm{Bs} 4 \mathrm{w}-$ ZYYgcSQ
Tradução da língua de sinais para a língua portuguesa (legenda do vídeo):

Absurdo! ABSURDO! A-B-S-U-R-D-O! Absurdo de verdade. O quê? O INES fechar!? Calma aí! Não dá pra engolir isso. Não dá. Não, por favor! Por favor, eu imploro. Peço pelo que há de mais sagrado. Parem tudo! Acordem! Divulguem. Fechar o INES, NÃO! Eu quero que vocês surdos pensem bem. Olhem só isso, defendem os surdos! Os surdos vão perder a convivência em língua de sinais, a cultura, a identidade. Perder isso pra sermos oprimidos numa inclusão de ouvintes? NÃO! Abram os olhos! Por favor! Eu peço a vocês: Não vamos deixar essa brutalidade acontecer. Os surdos vão perder a sua cultura. Estou chorando por dentro, meu coração dói. Por favor! Surdos, vamos discutir sobre isso. O MEC não pode mudar o INES. O INES é assim! Não podemos aceitar isso de braços cruzados. Levantem! Lutem! Conto com vocês e fiquem atentos.

FONTE: http://www.youtube.com/watch?v= yl6cfWmUrtU 
edições da Revista da Feneis: $n^{\circ} .40$ (2010a) e nº 41 (2010b). O vídeo de Nelson Pimenta provocou uma mobilização enorme pelo Brasil afora, convocando toda a comunidade surda brasileira para uma passeata histórica, que ocorreu em Brasília, nos dias 19 e 20 de maio de 2011.

A edição $n^{\circ} .41$ da Revista da Feneis (2011) registra uma matéria com a seguinte chamada: Qual a melhor escola para as crianças surdas? Existe cultura surda? A escola bilíngue é segregacionista? Pesquisadores discutem as várias faces da questão e apontam o bilinguismo como o melhor caminho para a educação dos surdos.

Somado a estes fatores de mobilização e alertas, o jornal $O$ Globo ${ }^{4}$ procurou a Profa. Patrícia Rezende (diretora de políticas educacionais da Feneis) para uma entrevista, que respondeu sobre a ameaça do fechamento do Colégio de Aplicação do INES. Na reportagem, de 29 de março de 2011, a professora denuncia que alunos não compartilham uma língua nas escolas convencionais:

Atual política de inclusão insiste em colocar crianças surdas junto com as ouvintes, sem haver um compartilhamento linguístico entre elas. Nesses espaços, as crianças surdas oriundas de famílias ouvintes não adquirem sua língua natural de forma espontânea, como as crianças ouvintes que compartilham a mesma língua da sua família interagindo e obtendo informações e, assim, construindo o conhecimento de mundo, que é aprofundado na escola. Como haver inclusão se não há aquisição linguística pela criança surda? (O GLOBO, 2011)

No dia seguinte, 30 de março de 2011, o Jornal $O$ Globo ${ }^{5}$ trouxe à tona o assunto novamente, com a manchete: "MEC nega fechamento de escolas especiais para surdos e cegos, desautorizando o anúncio feito pela diretora de Políticas de Educação Especial do MEC, Martinha Claret, sobre o fechamento dos Colégios de Aplicação do INES e do Instituto Benjamin Constant (escola para cegos)".

Apesar desta notícia aparentemente tranquila, não desistimos da mobilização para a passeata histórica em Brasília. Muitos vídeos foram produzidos por vários líderes surdos, pelo país todo, e também foi criado um abaixo-assinado intitulado "Em defesa da Educação de Surdos no INES", com coleta de assinaturas on-line e em papel, além de publicações em jornais de grande renome para que houvesse um impacto maior e significativo.

4 Disponível em: $<$ http://oglobo.globo.com/rio/para-professora-alunos-nao-compartilham-lingua-nas-escolas-convencionais-2804155\#ixzz2v3wJvK3d>. Acesso em: 28/02/2014.

5 Disponível em: $<$ http://oglobo.globo.com/rio/mec-nega-fechamento-de-escolas-especiais-para-surdos-cegos-2803604\#ixzz32Sk3513r>. Acesso em: 28/02/2014. 
Houve grande resistência por parte da comunidade surda; são resistências surdas no sentido de Perlin (2003, p. 104): "O surdo na experiência do ser surdo se sente o outro e as resistências, devido à imposição da experiência ouvinte quando não são acompanhadas de silêncio, são resistências povoadas de significados".

O Instituto Nacional de Educação de Surdos é uma escola centenária, a primeira escola de surdos no País, que abrigou e educou vários dos líderes surdos de todo o País, representando o berço e resistência da língua de sinais e da cultura surda. Alunos surdos, formados no INES, no retorno às suas cidades de origem, fundaram associações de surdos, o que propiciou a formação da Identidade Linguística da Comunidade Surda aflorada por todo o país. Por isso, consideramos o INES como o berço da nossa língua de sinais e da nossa cultura surda. Faz todo sentido essa mobilização ter repercutido em todo o País contra a ameaça de fechamento do INES. Abaixo (Figura 2), Fabio Selani, cartunista surdo, de Brasília, faz uma analogia entre o anúncio do Congresso de Milão ${ }^{6} \mathrm{e}$ o anúncio do MEC:

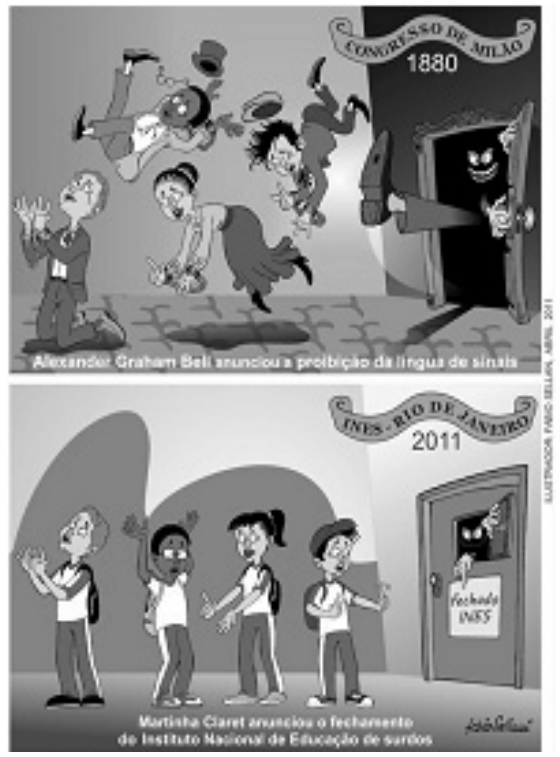

FIGURA 2 - A VOLTA DO CONGRESSO DE MILÃO

FONTE: Revista da Feneis (2011).

6 O Congresso de Milão é mundialmente conhecido pela comunidade surda como o evento que proibiu a língua de sinais na educação de surdos, banindo os professores surdos das escolas. 
Esta ilustração foi uma resposta ao comunicado do MEC ao fechamento do Colégio de Aplicação do INES, bem como às palavras ditas por Martinha Claret à Revista da Feneis (2010b), quando perguntada sobre a importância das escolas de surdos para a valorização da cultura e das identidades surdas. A resposta recebida foi:

[...] do ponto de vista da educação inclusiva, o MEC não acredita que a condição sensorial institua uma cultura. As pessoas surdas estão na comunidade, na sociedade e compõem a cultura brasileira. Nós entendemos que não existe cultura surda e que esse é um princípio segregacionista. As pessoas não podem ser agrupadas nas escolas de surdos porque são surdas. Elas são diversas. Precisamos valorizar a diversidade humana (FENEIS, 2010b, p. 23).

Quando os surdos produzem estes desenhos povoados de significados, os sentidos produzidos pela resistência surda afloram. Lopes e Veiga-Neto dizem a respeito que:

No caso dos discursos que tratam da inclusão dos surdos, por exemplo, quase sempre eles parecem ignorar a vontade do outro e concedem uma mínima possibilidade para o seu exercício de liberdade. Em nossos estudos, temos encontrado situações em que os ouvintes posicionam-se como os únicos capazes de dizer o que é melhor para a educação dos surdos. Não raro, é como se a racionalidade fosse uma faculdade ausente nos surdos, vistos como incapazes de se autoconduzir; consequentemente, o ouvintismo é assumido - pelos ouvintes, é claro... - como salvo-conduto para ações tutelares. (LOPES; VEIGA-NETO, 2011, p. 10)

Nós, os surdos, não queremos ser tutelados, queremos o exercício da liberdade pela forma e escolha linguística e cultural condizente com o nosso modo de viver e experienciar, de sermos surdos, diferente dos ouvintes. Somente nós, surdos, que sabemos o que é melhor para nós, da forma como precisamos ser educados, da forma como precisamos aprender, que é pela instrução direta em nossa língua de sinais, língua soberana da comunidade surda, que ajuda na formação da "Identidade Linguística da Comunidade Surda", como garante e expressa a Convenção sobre Direitos das Pessoas com Deficiência (BRASIL, 2009). 
Os dias 19 e 20 de maio de 2011 foram dias marcantes e históricos para a nossa vida; foram dias eternizados em nossos corações como representação da resistência surda contra a autoridade do Ministério da Educação de impor à educação de surdos aquilo que não nos atende.

Os dispositivos legais da Convenção sobre Direitos das Pessoas com Deficiência, promulgada no Brasil com status de Emenda Constitucional pelo Decreto 6.949/2009 (com base no Decreto Legislativo n ${ }^{\circ}$ 186, de 9 de julho de 2008, e conforme o que prevê o $\S 3^{\circ}$ do art. $5^{\circ}$ da Constituição Federal), dizem claramente que as pessoas com deficiência deverão fazer jus, em igualdade de oportunidades com as demais pessoas, a que sua identidade cultural e linguística específica seja reconhecida e apoiada, incluindo as línguas de sinais e a cultura surda (Artigo 30, § 4). O artigo 24, da mesma Convenção, diz que cabe aos estados-parte (governo) garantir a facilitação do aprendizado da língua de sinais, a promoção da identidade linguística da comunidade surda; e a garantia de que a educação de pessoas, inclusive crianças cegas, surdocegas e surdas, seja ministrada nas línguas e nos modos e meios de comunicação mais adequados a elas e em ambientes que favoreçam ao máximo seu desenvolvimento acadêmico e social.

Estas são algumas das nossas garantias legais, primordiais para defendermos nossas Escolas Bilíngues de Surdos. Por isso, após a histórica passeata, em maio de 2011, não paramos a nossa luta, tínhamos que carregar a nossa bandeira em defesa de Escolas Bilíngues de Surdos. Promovemos, em setembro de 2011, o marco em comemoração pelo Dia Mundial da Língua de Sinais, pelo Dia Mundial do Surdo, pelo Dia Nacional do Surdo, a fim de fincar a nossa luta pelas emendas específicas sobre a nossa educação no Plano Nacional de Educação, em tramitação no Congresso Nacional. Na figura 3, apresentamos o adesivo que divulgou as palestras que foram transmitidas em vídeo nos Seminários Estaduais em Defesa das Escolas Bilíngues para Surdos no Plano Nacional de Surdos - PNE, em 2011.

Os Seminários foram realizados simultaneamente em praticamente todas as capitais do País, em sua maioria em Assembleias Legislativas com a presença de vários parlamentares. Na ocasião, também entregamos propostas de emendas da Feneis para serem incorporadas ao texto-base do Plano Nacional da Educação - PNE.

Conseguimos mobilizar muitos parlamentares apoiando as nossas emendas, mas tivemos que procurar o Relator da Comissão Especial do PNE, o Deputado Federal Ângelo Vanhoni, o principal responsável pelo relatório do PNE, para que tivéssemos um texto específico, sem margens de dúvidas e manipulações conceituais sobre a educação bilíngue que queríamos. 


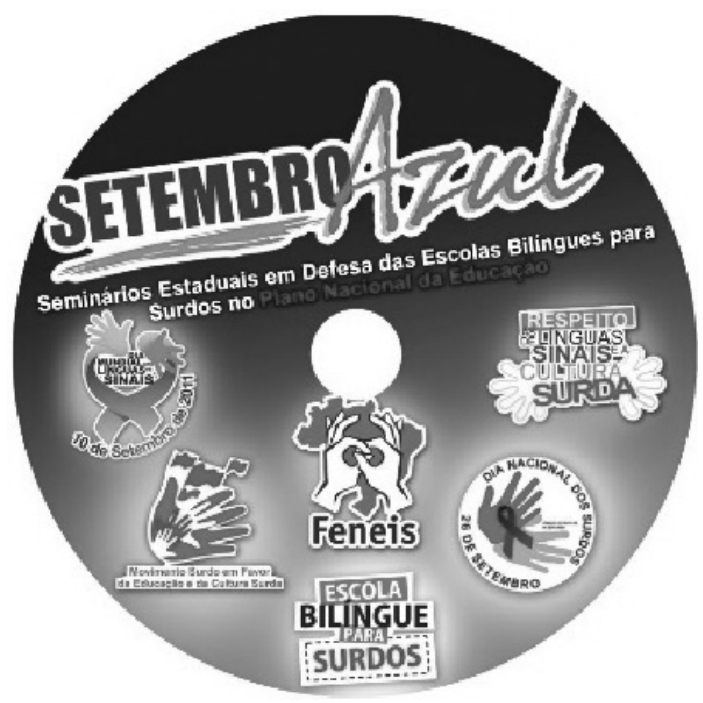

FIGURA 3 - SETEMBRO AZUL

FONTE: Acervo da Diretoria de Políticas Educacionais da Feneis.

Tentamos, por várias vezes, agendar uma reunião com o Deputado Federal Ângelo Vanhoni, sem sucesso, até que no dia 24 de abril de 2012 fomos à Brasília fazer uma passeata em comemoração a uma década de reconhecimento de Libras, e apresentar a nossa proposta de Política Nacional de Educação Bilíngue para Surdos para a então Ministra da Casa Civil, Gleisi Hoffman. Exatamente naquele dia, acontecera uma audiência pública sobre o PNE na Câmara dos Deputados e participamos do evento. Na ocasião, o Relator do PNE apresentava seu relatório e a Feneis conseguiu a audiência com o Deputado Vanhoni. Foi então que a instituição conseguiu expor os pontos primordiais para justificar a inclusão de escolas bilíngues para surdos no PNE. Saímos da reunião com a promessa de que ele iria analisar o assunto e apresentar o seu relatório em sua próxima audiência sobre o PNE na Câmara dos Deputados. Conseguimos o feito! Vejamos a seguir a manchete do Jornal da Câmara, número 2.789, ano 14, de 30 de maio de 2012 (Figura 4), que representou uma conquista para a comunidade surda brasileira: "Ensino especial e escolas bilíngues para surdos são incluídos em metas do Plano Nacional de Educação". 


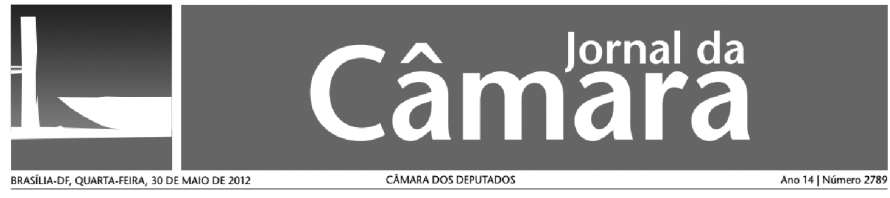

\section{Ensino especial e escolas bilíngues para surdos são incluídos em metas do Plano Nacional de Educação}

FIGURA 4 - ESCOLA BILÍNGUE NO PNE

FONTE: Acervo do Jornal da Câmara dos Deputados?

Um avanço e tanto, considerado o Projeto de Lei originalmente apresentado pelo MEC ao Congresso Nacional, que havia confiscado as escolas bilíngues de surdos reivindicadas na CONAE 2010. Vejamos a seguir:

Manter e aprofundar programa nacional de acessibilidade nas escolas públicas para adequação arquitetônica, oferta de transporte acessível, disponibilização de material didático acessível e recursos de tecnologia assistiva, e oferta da educação bilíngue em língua portuguesa e Língua Brasileira de Sinais - LIBRAS (BRASIL, 2010, grifo nosso).

Reconhecendo-se o pleito da comunidade surda e a força do Movimento frente à demanda pelo não fechamento das Escolas Federais - INES (Instituto Nacional de Educação de Surdos) e IBC (Instituto Benjamin Constant), frente à necessidade de se considerar mais de um modelo educacional, bem como frente à tramitação da meta 4 do PNE na Câmara dos Deputados parlamentares do Congresso Nacional, em especial o Relator do PNE na Câmara dos Deputados, acata-se e inclui-se no relatório do PNE o texto proposto pela Feneis:

Garantir a oferta de educação bilíngue, em Língua Brasileira de Sinais - LIBRAS como primeira língua e na modalidade escrita da Língua Portuguesa como segunda língua, aos alunos surdos e com deficiência auditiva de 0 (zero) a 17 (dezessete) anos, em escolas e classes bilíngues e em escolas inclusivas, nos termos do art. 22 do Decreto $\mathrm{n}^{\circ} 5.626$, de 22 de dezembro de 2005, e dos arts. 24 e 30 da Convenção Sobre os Direitos das Pessoas com Deficiência, bem como a adoção do Sistema Braille de leitura para cegos e surdocegos. (BRASIL, 2010, grifo nosso).

7 Disponível em: <http://www.camara.gov.br/internet/jornal/JC20120530.pdf>. 
Isso ocorreu no dia 29 de maio de 2012 e representou a importância da luta da comunidade surda para a construção parlamentar dos dispositivos legais condizentes com as especificidades linguísticas e culturais de surdos. Nessa ocasião, o então Ministro da Educação, Aloízio Mercadante, emitiu uma declaração para a imprensa, a qual mobilizou os pesquisadores e doutores surdos (até então, sete profissionais), para elaborar uma carta aberta ao Ministro da Educação ${ }^{8}$, cujos trechos mais relevantes seguem reproduzidos:

Nós, surdos, militantes das causas dos nossos compatriotas surdos, apelamos a Vossa Excelência pelo nosso direito de escolha da educação que melhor atende aos surdos brasileiros que têm a Libras como primeira língua. Concordamos que "O Brasil tem que ter 100\% das crianças e jovens com deficiência na escola", sim, mas não concordamos que a escola regular inclusiva seja o único e nem o melhor espaço onde todas essas crianças e jovens conseguem aprender com qualidade. Afirmar que "A política de educação inclusiva permitiu um crescimento espetacular, de forma que os estudantes com deficiência convivem com os outros alunos e os outros alunos convivem com eles" nos angustia, pois queremos conviver com os demais cidadãos brasileiros, sim, mas queremos, acima de tudo, que a escola nos ensine.

[...] Escrevemos essa carta, juntos, para dizer-lhe, respeitosamente, mas com a ênfase necessária à gravidade que o tema exige, que suas falas não têm fundamento científico ou empírico, conforme mostram nossas próprias pesquisas e as de um sem número de outros pesquisadores brasileiros. Várias pesquisas mostram que os surdos melhor incluídos socialmente são os que estudam nas Escolas Bilíngues, que têm a Língua de Sinais brasileira, sua língua materna, como primeira língua de convívio e instrução, possibilitando o desenvolvimento da competência em Língua Portuguesa escrita, como segunda língua para leitura, convivência social e aprendizado. Não somos somente nós que defendemos essa tese. Reforçamos que há um número relativamente grande de mestres e doutores, pesquisadores de diversas áreas de conhecimento, além de professores de ensino básico e superior, que identificam essa realidade e atuam nessa luta conosco. Todos os pesquisadores sérios proclamam que as ESCOLAS BILÍNGUES PARA SURDOS, cujas línguas de instrução e convívio são a Libras (L1) e o Português escrito (L2), são os melhores espaços acadêmicos para a aprendizagem e inclusão educacional de

8 Elaborada pelos sete primeiros doutores surdos brasileiros, que atuam nas áreas de educação e linguística, em diferentes instituições de ensino públicas, federais e estaduais: Ana Regina e Souza Campello, Gladis Terezinha Taschetto Perlin, Karin Lilian Strobel, Marianne Rossi Stumpf, Patrícia Luiza Ferreira Rezende, Rodrigo Rosso Marques e Wilson de Oliveira Miranda. 
crianças e jovens surdos. [...] Dói-nos verificar que esses espaços de aquisição linguística e convivência mútua entre os pares falantes da língua de sinais têm sido rotulados de espaços e escolas "segregacionistas". Isso não é verdade! Escola segregacionista e segregadora é a que impõe que alunos surdos e ouvintes estejam no mesmo espaço sem que tenham as mesmas oportunidades de acesso ao conhecimento. $\mathrm{O}$ fato de os alunos surdos estudarem em Escolas Bilíngues, onde são considerados e aceitos como uma minoria linguística, não significa segregar. A Libras é a primeira língua da maioria dos surdos brasileiros e não uma língua falada apenas por pessoas "deficientes". [...] A postura segregadora não parte de nós, mas dos que não aceitam nossas especificidades e necessidades. Essa postura é tão inaceitável linguisticamente, antropologicamente, filosoficamente, quanto dizer que as línguas dependem das raças ou do clima. Insistimos, portanto, em que as escolas que oferecem um ensino bilíngue para crianças e jovens surdos se baseiem não na deficiência, mas na língua de sinais, uma língua plenamente acessível para todos os que têm a visão como principal via de acesso comunicativo, informacional e instrucional (CARTA Aberta ao Ministro da Educação, 2012).

Convém relembrar, também, o que enfaticamente determina a Convenção Internacional sobre os Direitos das Pessoas com Deficiência, no seu Art. $4^{\circ}$, inciso 3:

Na elaboração e implementação de legislação e políticas para executar a presente Convenção e em outros processos de tomada de decisão relativos às pessoas com deficiência, os Estados-Partes deverão estreitamente consultar e ativamente envolver pessoas com deficiência, inclusive crianças com deficiência, por intermédio de suas organizações representativas (BRASIL, 2009).

Apesar desta garantia constitucional, após a tramitação do PNE na Câmara dos Deputados, que acatou a nossa proposta, o projeto de Lei (PL 8035/10 PNE) foi ao Senado. Primeiramente, na Comissão de Assuntos Econômicos, o texto foi alterado à nossa revelia, conforme destacamos abaixo:

Garantir a oferta de educação bilíngue, em Língua Brasileira de Sinais - LIBRAS como primeira língua e na modalidade escrita da Língua 
Portuguesa como segunda língua, aos alunos surdos e com deficiência auditiva de 0 (zero) a 17 (dezessete) anos, em escolas e classes bilíngues emelusivas, nos termos do art. 22 do Decreto $n^{0} 5.626$, de 22 de dezembro de 2005, e dos arts. 24 e 30 da Convenção Sobre os Direitos das Pessoas com Deficiência, bem como a adoção do Sistema Braille de leitura para cegos e surdocegos (PLC 103/2012, grifo nosso).

Esta alteração aconteceu em maio de 2013, pelo relator da Comissão de Assuntos Econômicos, Senador José Pimentel. Apesar de várias manifestações da comunidade surda durante as reuniões da Comissão, das várias tentativas de agendamento de audiência dele com os líderes surdos do Ceará, estado de origem do Senador, não houve resposta e não fomos recebidos. Ele preferiu atender à "facção" governista que propôs excluir duas preposições e uma palavra ("e"/ "em"/ "escolas"), desconsiderando nossa luta e fazendo um jogo de palavras por meio do qual qualquer escola poderia ser considerada bilíngue.

Devido a esta alteração do texto do PNE, a nossa revelia, agendamos nova passeata em Brasília, no dia 14 de agosto de 2013. Fizemos o percurso desde o Museu Nacional até o Congresso Nacional; marcamos presença no Senado; chamamos a atenção dos parlamentares para atenderem ao nosso pleito de voltar à redação dada pelo Relator Ângelo Vanhoni da Câmara dos Deputados.

O projeto do PNE seguiu em tramitação para a Comissão de Constituição, Justiça e Cidadania, cujo relator foi o Senador Vital do Rêgo que, apesar de tê-lo encontrado pessoalmente, não nos atendeu, permanecendo o forte lobby do MEC que solicitou a retirada apenas da palavra "inclusivas", sob a alegação de que seria um texto consensuado, conforme segue:

Garantir a oferta de educação bilíngue, em Língua Brasileira de Sinais - LIBRAS como primeira língua e na modalidade escrita da Língua Portuguesa como segunda língua, aos alunos surdos e com deficiência auditiva de 0 (zero) a 17 (dezessete) anos, em escolas e classes bilíngues inetusives nos termos do art. 22 do Decreto ${ }^{\circ} 5.626$, de 22 de dezembro de 2005, e dos arts. 24 e 30 da Convenção Sobre os Direitos das Pessoas com Deficiência, bem como a adoção do Sistema Braille de leitura para cegos e surdocegos. [grifo nosso].

Não nos tranquilizamos em face do histórico de expedição de Notas Técnicas (BRASIL, 2013) emitidas pela Diretoria de Políticas de Educação 
Especial, assinada pela Sra. Martinha Claret. Trata-se de notas que explicam sobre a educação bilíngue para surdos, sob a afirmação de que esta "deve" ser realizada por meio de tradução e interpretação, e realizada no AEE - Atendimento Educacional Especializado, de forma complementar, ou seja, no contraturno da escolarização. Estas afirmações envolvem concepções errôneas sobre a nossa educação, rebatidas pela nota de esclarecimento da Feneis, expedida em setembro de 2013, da qual destacamos um fragmento que trata da alteração da redação do PNE:

Ora, por meio desta redação sem consenso, o MEC quer declarar que escolas e classes bilíngues são sinônimo de escolas comuns, contando apenas com a presença de intérpretes de Libras. Afirmamos que querem esmaecer a nossa conquista e querem ir contra o que estabelece no Decreto 5625/2005: que escolas bilíngues são uma coisa e escolas comuns da rede regular de ensino são outra coisa (cf. Artigo 22-II). Nós, surdos, precisamos de nossas escolas e classes bilíngues! Conclamamos a que os educadores e a sociedade nos ajudem a defender o direito que temos de adquirir a nossa língua em um ambiente linguisticamente favorável - o que uma escola comum nunca poderá propiciar. O MEC desconsidera que, em uma escola bilíngue para surdos, as aulas devam ser ministradas diretamente em LIBRAS, com metodologias específicas. Vejamos os três espaços educacionais:

- escolas bilíngues (onde a língua de instrução é a Libras e a Língua Portuguesa é ensinada como segunda língua, mediada pela língua de instrução, Libras; essas escolas se instalam em espaços arquitetônicos próprios e nelas devem atuar professores bilíngues, sem mediação por intérpretes e sem a utilização do português sinalizado. Os alunos não precisam estudar no contraturno em classes de Atendimento Educacional Especializado - AEE, dado que a forma de ensino é adequada e não demanda atendimento compensatório);

- as classes bilíngues (que podem ocorrer nos municípios em que a quantidade de surdos não justificar a criação de uma escola bilíngue específica para surdos) podem existir na mesma edificação de uma escola inclusiva; - nas escolas inclusivas, onde o português oral é a língua de instrução, algumas vezes mediada por intérpretes, o aluno surdo tem que estudar dois períodos, participando do Atendimento Educacional Especializado (AEE) no contraturno e são matriculados duas vezes (dupla matrícula) (FENEIS, 2013 ${ }^{9}$.

9 Feneis. Nota sobre Educação de Surdos na meta 4 do PNE. Rio de Janeiro, 2013. 
Esse posicionamento reafirma a argumentação por ocasião de nosso "Setembro Azul", ocorrido no dia 26 de setembro de 2011, em comemoração ao Dia Nacional do Surdo, quando os líderes surdos se mobilizaram por todo o País para a entrega da carta-denúncia dos surdos falantes da Língua Brasileira de Sinais (Libras) ao Ministério Público Federal sobre a Política Nacional de Educação Especial na Perspectiva da Educação Inclusiva imposta à Educação de Surdos pela Secretaria de Alfabetização, Diversidade e Inclusão do Ministério da Educação, na qual foram apresentados dados estatísticos sobre a evasão escolar dos surdos. Na ocasião, esclareceu-se que:

Entre 2006 e 2009, foram fechadas 13.552 vagas em classes e escolas específicas para alunos surdos e com deficiência auditiva, e apenas 4.450 novas matrículas de alunos surdos e com deficiência auditiva surgiram em classes comuns do ensino regular, o que nos permite dizer que, entre 2006 e 2009, 9.102 alunos surdos e com deficiência auditiva foram excluídos do sistema escolar. Mais ainda, se entre 2002 e 200619.716 novos alunos surdos e com deficiência auditiva ingressaram no sistema educacional geral do país, a partir da política de fechamento das classes e escolas específicas, esse acréscimo baixou, em 2009, para 10.614! Os dados de 2010 sobre o conjunto de alunos surdos e com deficiência auditiva merecem uma análise à parte. Segundo o Censo Escolar 2010 (INEP/MEC), houve uma diminuição na Educação Infantil, entre 2008 e 2010, de 23.856 matrículas de crianças com deficiência. Em 2008, havia 93.297 matrículas desse segmento; em 2009, 74.779; em 2010, 69.441. Nada indica, portanto, que a elevação do número de matrículas de surdos e com deficiência auditiva na educação básica, em 2010, se deva a uma maior capacidade do sistema de incluir e manter crianças no início de sua vida escolar. Como se explicaria, então, esse aumento? Não resta dúvida, é forte a hipótese de que ele seria causado pelo retorno aos estudos de jovens surdos e com deficiência auditiva na modalidade EJA (Educação de Jovens e Adultos). Pelo menos, desde 2007 (quando houve uma queda de 5,8\% do número de pessoas com deficiência no sistema de educação básica). O INEP agrupa, em sua publicação anual, o número de matrículas do ensino regular ao da educação de jovens e adultos. Assim, esses dados da inclusão de surdos e pessoas com deficiência auditiva no ensino regular expressam também o número desses alunos "fora da faixa etária", que retornam à escola após terem-na abandonado (ou após terem sido dela excluídos, dada à alienação linguística a qual são submetidos); entre eles, encontram-se alunos surdos que retornam aos estudos após terem adquirido a Língua de Sinais Brasileira fora da escola, podendo 
então a ela retornar em condições de acompanhar a aula pelo intermédio da "interpretação" (do intérprete).

Além desses relevantes dados, temos o amparo científico de uma investigação de grande magnitude realizada pelo Professor da Universidade de São Paulo (USP), Fernando Capovilla, que realizou uma pesquisa quantitativa financiada pelo MEC, através de seus órgãos, como o Capes e o INEP e pelo Ministério da Ciência, Tecnologia e Inovação, através do CNPq (Conselho Nacional de Desenvolvimento Científico e Tecnológico). Foi uma pesquisa de grande alcance, que atingiu todas as regiões do país e representa um dos maiores conjuntos de dados já reunidos em todo o mundo sobre o desenvolvimento escolar dos estudantes surdos brasileiros durante um período de dez anos. A pesquisa é intitulada "Programa de Avaliação Nacional do Desenvolvimento da Linguagem do Surdo Brasileiro (Pandesb)", realizada entre 2001 e 2011, examinando 9.200 estudantes surdos brasileiros do $1^{\circ}$. ano do ensino fundamental, até o ensino superior, em quinze Estados brasileiros. Cada um dos 9.200 estudantes surdos foi examinado durante 26 horas, em diversas baterias de testes estandardizados, que avaliaram diversas competências como: leitura alfabética e orofacial, compreensão de leitura de textos, vocabulário de escrita e qualidade ortográfica da escrita, vocabulário em Libras e Português, memória de trabalho, entre outros. Vejamos o que diz Capovilla a respeito da pesquisa:

[...] os estudantes surdos aprendem mais e melhor em escolas bilíngues (escolas especiais que ensinam em Libras e Português) do que em escolas monolíngues (escolas comuns que ensinam em Português apenas). [...] competências como decodificação de palavras e reconhecimento de palavras, compreensão de leitura de textos, vocabulário em Libras, dentre outras, foram significativamente superiores em escolas bilíngues do que em escolas comuns. (CAPOVILLA, 2011, p. 86 e 87, grifos nossos).

A IDA (International Disability Alliance), órgão da sociedade civil internacional, que aglutina as entidades internacionais dos diversos segmentos das pessoas com deficiência, inclusive o WFD - World Federation of the Deaf, foi a principal articuladora social responsável pela realização da Convenção Internacional das Pessoas com Deficiência, no âmbito das Nações Unidas (e que, por isso mesmo, continua a atuar junto à ONU no acompanhamento e fiscalização da implementação da Convenção). Segue um trecho do documento elaborado 
pela IDA, na Reunião da Cúpula do Conselho Econômico e Social (ECOSOC), realizada em julho de 2011, para a Revisão Ministerial Anual e que trata da educação bilíngue de surdos:

[...] As crianças surdas precisam ser incluídas primeiramente através da língua e da cultura mais apropriada antes de serem incluídas nas diferentes áreas da vida em estágios posteriores, por exemplo, no ensino médio e superior, bem como na vida profissional. O apoio dos pares é necessário. (ONU, 2011)

Foi por estas proposições e comprovações científicas e legislativas que a Diretora de Políticas Educacionais da Feneis, Profa. Dra. Patrícia Rezende, apresentou seu discurso na mesa da audiência pública do PNE, no dia 5 de novembro de 2013, convocada pela Comissão da Educação do Senado, sob a relatoria do Senador Álvaro Dias.

Conseguimos sensibilizar o Senador Álvaro Dias para que a redação dada pelo Deputado Vanhoni na Câmara dos Deputados voltasse ao texto final do PNE. A política é feita de negociações intensas devido ao forte lobby dos lados opostos. O MEC não respeitou a construção parlamentar da comunidade surda, tentou a todo custo retirar palavras mudando o sentido do nosso texto, o qual foi fruto de intensas lutas e batalhas. Nesse caso fazem sentido as palavras de Lane (1992, p. 103): "A educação é o campo de batalha onde minorias linguísticas ganham ou perdem os seus direitos."

Somos uma minoria linguística na luta pela preservação da língua de sinais e sua instituição como língua de instrução em nossa educação; não queremos a educação inclusiva como é preconizada, e muito menos a educação especial, queremos uma educação linguística, uma política linguística traçada pelo nosso "ser surdo". Tanto que lutamos para que fosse criado um Grupo de Trabalho no Ministério da Educação em que a Feneis tivesse a representação maior para traçar metas e recomendações para a realização da Política Linguística. Enfatizamos, neste GT, a desvinculação da educação linguística de surdos da educação especial, por não vermos sentido que sejamos alocados e programados pela Diretoria de Políticas da Educação Especial, pois esse historicismo tem rendido à nossa educação a imposição de uma política de educação inclusiva que ora aloca os alunos surdos em escolas comuns com Atendimento Educacional Especializado, entendido como oferta educacional esporádica e fragmentada, no contraturno da aula, realizada durante poucas horas por semana, sem atender a nossa necessidade de uma Identidade Linguística da Comunidade Surda. 
Depois de três longínquos anos de luta no Congresso Nacional acompanhando a tramitação do Plano Nacional de Educação (PNE), com intensas negociações nos bastidores e audiências públicas, no dia 28 de maio de 2014, finalmente foi aprovada a redação do plano na Câmara dos Deputados e sancionada pela Presidenta da República do Brasil, Dilma Roussef, em junho de 2014.

Foi assim que lutamos no passado e é assim que continuamos lutando, por uma qualidade que condiga com uma política linguística, com uma educação linguística, com uma educação bilíngue. Nada vai em frente quando não há luta; a batalha encerra-se, entretanto, as lutas não cessam. A mobilização em defesa de nossas Escolas Bilíngues de Surdos vem dos primórdios, mas com maior intensidade a partir da explosão do Movimento Surdo, quando na ameaça do fechamento da nossa escola centenária. Enfim, estamos construindo a nossa política da verdade: as escolas bilíngues de surdos não são segregadas, não são segregadoras e nem segregacionistas como tem alardeado tanto o Ministério da Educação. Pelo contrário, são espaços de construção do conhecimento para o cumprimento do papel social de tornar os alunos cidadãos verdadeiros, conhecedores e cumpridores dos seus deveres e defensores dos seus direitos, o que, em síntese, leva à verdadeira inclusão.

\section{REFERÊNCIAS}

ATHIÉRES, Philippe. Dizer a atualidade: o trabalho de diagnóstico em Michel Foucault. In: GROS, Frédéric (Org.). Foucault: a coragem da verdade. São Paulo: Parábola Editorial, 2004.

BRASIL. Câmara dos Deputados. Projeto de Lei no ${ }^{0}$.035-B de 2010. Aprova o Plano Nacional de Educação - PNE e dá outras providências. Brasília - DF, Comissão de Constituição e Justiça e de Cidadania, 2010.

. Decreto n. 6.949, de 25 de agosto de 2009. Promulga a Convenção Internacional sobre os Direitos das Pessoas com Deficiência e seu Protocolo Facultativo, assinados em Nova York, em 30 de março de 2007. Legislação Federal. Diário Oficial da União, Brasília, DF, 26 ago. 2009. Disponível em: < http://www.planalto.gov.br/ccivil_03/_ato20072010/2009/decreto/d6949.htm>. Acesso em 28/02/2014.

. Lei no 13.005, de 25 de junho de 2014. Aprova o Plano Nacional de Educação e dá outras providências. Diário Oficial da União, Brasília, DF, 26 jun. 2014. Seção 1, Edição Extra. 
Ministério da Educação. Secretaria de Alfabetização e Diversidade. Relatório sobre a Política Linguística de Educação Bilíngue - Língua Brasileira de Sinais e Lingua Portuguesa do Grupo de Trabalho, designado pelas Portarias n 1.060/2013 e n ${ }^{\circ}$ 91/2013 do MEC/SECADI. Brasília, fevereiro de 2014. Disponível em: <http://www. bibliotecadigital.unicamp.br/document $/$ ?code $=56513>$. Acesso em: 10/03/2014.

. Ministério da Educação. Secretaria de Alfabetização. NOTA TÉCNICA N ${ }^{\circ} 055 /$ 2013. Orientação à atuação dos Centros de AEE, na perspectiva da educação inclusiva. MEC/SECADI/DPEE. 10/05/2013.

CAPOVILLA, F. C. Sobre a falácia de tratar as crianças ouvintes como se fossem surdas, e as surdas, como se fossem ouvintes ou deficientes auditivas: pelo reconhecimento do status linguístico especial da população escolar surda. In: SÁ, Nídia Regina L. de. Surdos: qual escola? Manaus: Valer, 2011.

CARTA Aberta ao Ministro da Educação. 08 de junho de 2012. Disponível em: < http:// webcache.googleusercontent.com/search?q=cache:Cl-fMYM9uRcJ:lenereispvh. blogspot.com/2012/06/carta-aberto-dos-doutores-surdos-ao.html+\&cd=1\&hl=pt-BR\&ct $=\mathrm{clnk} \& \mathrm{gl}=\mathrm{br}>$. Acesso em: 22/02/2014.

DEFICIENTES visuais e auditivos temem possibilidade de perder escolas especiais. O Globo, Rio de Janeiro, 30 de março de 2011. Disponível em: < http://oglobo.globo. $\mathrm{com} /$ rio/deficientes-visuais-auditivos-temem-possibilidade-de-perder-escolas-especiais-2804151\#ixzz2v3xV06eQ>. Acesso em: 28/02/2014.

ENSINO especial e escolas bilíngues para surdos são incluídos em metas do Plano Nacional de Educação. Jornal da Câmara, Brasília, 30 de maio de 2012. Disponível em: $<$ http://www.camara.gov.br/internet/jornal/JC20120530.pdf>. Acesso em 28/02/2014.

FENEIS. Federação Nacional de Educação e Integração dos Surdos. A Luta da Comunidade Surda Brasileira pelas Escolas Bilingues para Surdos no Plano Nacional da Educação - PNE. Rio de Janeiro, julho de 2013.

. Carta-denúncia dos surdos falantes da Língua Brasileira de Sinais (LIBRAS) ao Ministério Público Federal sobre a Política Nacional de Educação Especial na Perspectiva da Educação Inclusiva imposta à Educação de Surdos pela Secretaria de Alfabetização, Diversidade e Inclusão do Ministério da Educação. Rio de Janeiro, setembro de 2011. de 2011 .

. Nota sobre a International Disability Alliance - IDA. Rio de Janeiro, setembro

. Revista da Feneis. Publicação trimestral da Federação Nacional de Educação e Integração dos Surdos, n. 40, jun./ago. 2010a. (ISSN 1981-4615).

. Revista da Feneis. Publicação trimestral da Federação Nacional de Educação e Integração dos Surdos, n. 41, set./nov. 2010b. (ISSN 1981-4615). 
. Revista da Feneis. Publicação trimestral da Federação Nacional de Educação e Integração dos Surdos, n. 44, jun./ago. 2011. (ISSN 1981-4615).

FOUCAULT, Michel. Microfísica do poder. Rio de Janeiro: Graal, 1979.

LANE, Harlan. A máscara da benevolência: a comunidade surda amordaçada. Lisboa: Instituto Piaget, 1992.

LOPES, Maura; VEIGA-NETO, Alfredo. Inclusão como dominação do outro pelo mesmo. VII Colóquio Internacional Michel Foucault. São Paulo: PUC-SP, 2011. Disponível em: <http://www.fe.unicamp.br/TEMPORARIOS/veiga-neto-lopes-inclusao-como-dominacao.pdf>. Acesso em: 28/02/2014.

LUCAS, Regiane. Conferência Nacional de Educação rejeita proposta que apoia a escola de surdos. Revista da Feneis. Publicação trimestral da Federação Nacional de Educação e Integração dos Surdos, n. 40, set./nov. 2010. (ISSN 1981-4615).

. Surdos no Planalto: quatro mil pessoas e uma agenda política intensa foram suficientes para que o centro nervoso do poder voltasse a atenção para a principal demanda dos surdos: a escola bilíngue. Revista da Feneis. Publicação trimestral da Federação Nacional de Educação e Integração dos Surdos, n. 44, jun./ago. 2011. (ISSN 1981-4615).

LUCAS, Regiane; MADEIRA, Diogo. Educação de Surdos: em repúdio às declarações do MEC, pesquisadores defendem bilinguismo e pedagogia surda. Revista da Feneis. Publicação trimestral da Federação Nacional de Educação e Integração dos Surdos, n. 40, jun./ago. 2010. (ISSN 1981-4615).

MEC nega fechamento de escolas especiais para surdos e cegos. O Globo, Rio de Janeiro, 30 de março de 2011. Disponível em: <http://oglobo.globo.com/rio/mec-nega-fechamento-de-escolas-especiais-para-surdos-cegos-2803604\#ixzz32Sk3513r>. Acesso em 28/02/2014.

ORGANIZAÇÃO DE NAÇÕES UNIDAS. Reunião da Cúpula do Conselho Econômico e Social (ECOSOC) com membros da International Disability Alliance (IDA), Nova York, 4 a 8 de julho de 2011, Revisão Ministerial Anual.

PARA PROFESSORA, alunos não compartilham a língua nas escolas convencionais. O Globo, Rio de Janeiro, 29 de março de 2011. Disponível em: <http://oglobo.globo. com/rio/para-professora-alunos-nao-compartilham-lingua-nas-escolas-convencionais-2804155\#ixzz2v3wJvK3d>. Acesso em: 28/02/2014.

PLC 103/2012. Parecer: Senador José Pimentel (PT). Disponível em: <http://www. josepimentel.com.br/sites/default/files/PLC1032012_RelatorioCAE_SenadorJosePimentel.pdf $>$.

PERLIN, Gladis. O ser e o estar sendo surdos: alteridade, diferença e identidade. Tese (Doutorado) - Programa de Pós-Graduação em Educação, Universidade Federal do Rio Grande do Sul. Porto Alegre, 2003. 
CAMPELLO, A. R.; REZENDE, P. L. F. Em defesa da escola bilíngue para surdos: a história...

SELANI, Fábio. Arte Surda. Revista da Feneis. Publicação trimestral da Federação Nacional de Educação e Integração dos Surdos, n. 44, jun./ago. 2011. (ISSN 1981-4615).

Texto recebido em 25 de julho de 2014. Texto aprovado em 07 de agosto de 2014. 